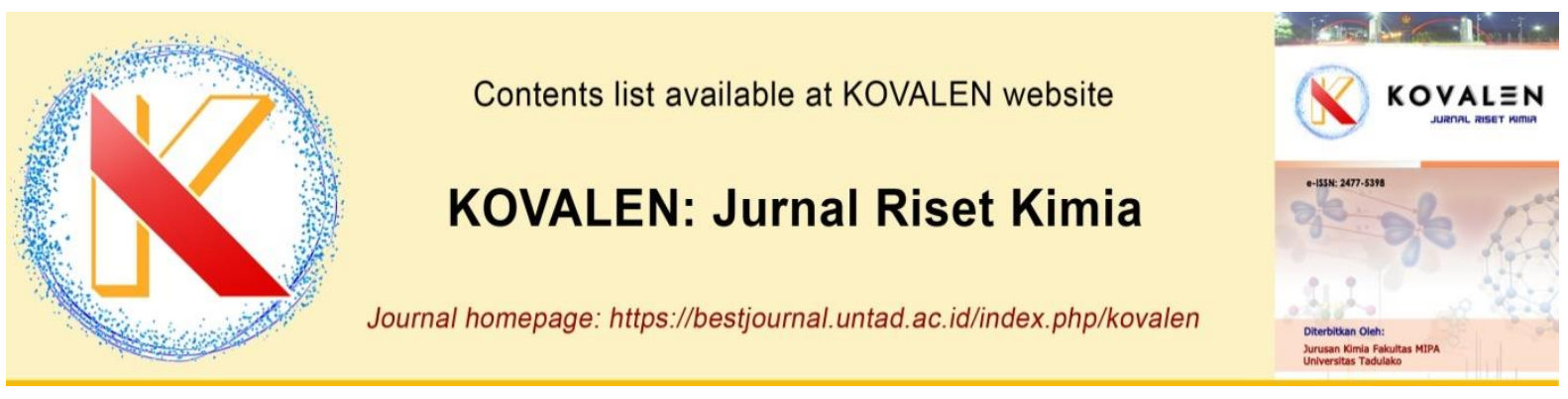

\title{
Perubahan Bilangan Peroksida pada Blending VCO-Ekstrak Likopen Buah Tomat Berdasarkan Perbandingan Rasio dan Lama Penyimpanan
}

\section{[Peroxide Value Changes on Blending of VCO and Extract of Tomato Lycopene Based on Ratio Comparison and Storage Time]}

\author{
Muqasyifah*, Nurhaeni, Syamsuddin, Khairuddin \\ Jurusan Kimia, Fakultas Matematika dan Ilmu Pengetahuan Alam, Universitas Tadulako, \\ J. Soekarno-Hatta Km. 9, Kampus Bumi Tadulako, Palu, Indonesia \\ *Corresponding author: muqasyifah08@gmail.com
}

\begin{abstract}
Utilizing of lycopene extract in VCO has serve as antioxidant agent that protected VCO from oxidation process during storage. Belnding of $\mathrm{VCO}$ and tomato lycopene extract has been done that purpose to determine changes in peroxide number in the mixture of VCO-lycopene extract tomatoes based on comparison of ratios and length of storage. Peroxide contents from the mixture of tomato extract with VCO were determined using a spectrophotometric method at a wavelength of $500 \mathrm{~nm}$. The results showed that the best results were obtained at a ratio of $40: 3(\mathrm{v} / \mathrm{w})$ with peroxide numbers $0.08 \mathrm{meq} \mathrm{O}_{2} / \mathrm{kg}, 1.38 \mathrm{meq} \mathrm{O} / \mathrm{kg}, 1.84 \mathrm{meq} \mathrm{O}_{2} / \mathrm{kg}, 3.21$ meq $\mathrm{O}_{2} / \mathrm{kg}, 3.46$ meq $\mathrm{O}_{2} / \mathrm{kg}$ and 3.83 meq $\mathrm{O}_{2} / \mathrm{kg}$ respectively. Peroxide numbers increased with increasing storage time, the highest increase occured at week 3 at a ratio of $40: 1(\mathrm{v} / \mathrm{w})$ which was equal to $9.62 \mathrm{meq} \mathrm{O}_{2} / \mathrm{kg}$. The addition of lycopene was better at reducing the VCO oxidation process than without the addition of lycopene.
\end{abstract}

Keywords : peroxide value, VCO, lycopene, duration of storage, ratio comparison.

ABSTRAK. Penggunaan ekstrak likopen dalam VCO berfungsi sebagai antioksidan, sehingga melindungi VCO dari proses oksidasi selama penyimpanan. Blending VCO dan ekstrak likopen tomat telah dilakukan dengan tujuan untuk mengetahui perubahan bilangan peroksida pada blending VCO-ekstrak likopen tomat berdasarkan perbandingan rasio dan lama penyimpanan. Bilangan peroksida ditentukan menggunakan metode spektrofotometri pada panjang gelombang $500 \mathrm{~nm}$. Hasil penelitian menunjukkan bahwa hasil terbaik diperoleh pada rasio 40:3 (v/b) dengan bilangan peroksida berturut-turut yaitu 0,08 meq $\mathrm{O}_{2} / \mathrm{kg}, 1,38 \mathrm{meq} \mathrm{O} / \mathrm{kg}, 1,84 \mathrm{meq}$ $\mathrm{O}_{2} / \mathrm{kg}, 3,21 \mathrm{meq} \mathrm{O}_{2} / \mathrm{kg}, 3,46 \mathrm{meq} \mathrm{O}_{2} / \mathrm{kg}$ dan $3,83 \mathrm{meq} \mathrm{O}_{2} / \mathrm{kg}$. Bilangan peroksida meningkat seiring bertambahnya waktu penyimpanan, peningkatan tertinggi terjadi pada minggu ke-5 pada rasio 40:1 (v/w), yaitu sebesar 9,87 meq $\mathrm{O}_{2} / \mathrm{kg}$. Penambahan likopen lebih baik dalam menurunkan proses oksidasi VCO dibandingkan dengan tanpa penambahan likopen.

Kata kunci : bilangan peroksida, VCO, likopen, lama penyimpanan, perbandingan rasio

Riwayat artikel: Diterima 15 Julli 2019, Disetujui 21 Agustus 2020

Cara sitasi: Muqasyifah., Nurhaeni., Syamsuddin., \& Khairuddin. (2020). Perubahan Bilangan Peroksida pada Blending VCO-Ekstrak Likopen Buah Tomat Berdasarkan Perbandingan Rasio dan Lama Penyimpanan. KOVALEN: Jurnal Riset Kimia, 6(2): 112117.

DOI: https://doi.org/10.22487/kovalen.2020.v6.i2.13132 


\section{LATAR BELAKANG}

Penelitian tentang produksi likopen dari buah tomat telah beberapa kali dilakukan. Mappiratu et al. (2010) dalam penelitiannya melakukan produksi likopen dari tomat afkiran (rusak) dan menghasilkan kadar likopen tertinggi sebesar $2,91 \%$, sedangkan Wenli et al. (2001) dalam penelitiannya melakukan produksi likopen dari tomat segar menghasilkan kadar likopen sebesar 3-5 $\mathrm{mg} / 100$ gram. Produksi likopen dari tomat afkiran akan menghasilkan kadar likopen lebih tinggi dibanding tomat kualitas baik. Likopen dapat dimanfaatkan sebagai agen antioksidan, seperti pada produk minyak kelapa ataupun virgin coconut oil (VCO)

Berbagai metode ekstraksi telah dikembangkan untuk menghasilkan minyak kelapa dengan kualitas yang baik. Peningkatkan kualitas VCO dapat dilakukan dengan beberapa metode, salah satunya, yaitu dengan menambahkan bahan alam seperti buah dan rempah-rempah. Penambahan bahan dalam VCO dapat menghambat proses oksidasi minyak. Penggunaan senyawa antioksidan dapat menghambat proses oksidasi, walaupun tetap terjadi oksidasi dengan bertambahnya waktu penyimpanan tetapi banyaknya peroksida yang terbentuk lebih sedikit dibandingkan minyak tanpa penggunaan senyawa antioksidan (Cikita et al., 2016). Koski et al, (2002) juga menyatakan bahwa dalam industri pangan, likopen tomat dapat digunakan sebagai pewarna alami dan mencegah kerusakan bahan pangan akibat oksidasi. Likopen dari buah tomat yang bersifat antioksidan berpotensi untuk mencegah oksidasi pada VCO sehingga bilangan perosida akan lebih rendah.
Bilangan peroksida menjadi parameter penting untuk melihat tinggkat oksidasi VCO. Penelitian Momuat et al. (2009) dengan menggunakan ekstrak tomat sebanyak 10\% dalam pembuatan VCO dapat menghambat reaksi oksidasi, sehingga bilangan peroksidanya lebih rendah yaitu sebesar 0,145 meq $\mathrm{O}_{2} / \mathrm{kg}$, sedangkan dalam penelitian Nodjeng et al. (2013) yang menentukan kualitas minyak VCO dengan variasi menggoreng sebanyak tiga kali pengulangan diperoleh bilangan peroksida pada VCO tanpa penambahan wortel lebih besar dibandingkan dengan VCO yang ditambahkan wortel dengan bilangan peroksida setelah penambahan wortel secara berurutan yaitu 2 meq $\mathrm{O}_{2} / \mathrm{kg}$ dan 1 meq $\mathrm{O}_{2} / \mathrm{kg}$, sehingga minyak $\mathrm{VCO}$ dengan penambahan wortel memiliki kualitas yang lebih baik dibandingkan dengan VCO tanpa penambahan wortel. Kajian tentang rasio likopen tomat dan VCO terhadap bilangan perosida VCO belum pernah dikaji sebelumnya, sehingga penelitian tentang kualitas VCO-ekstrak likopen tomat perlu dilakukan.

\section{METODE PENELITIAN}

\section{Peralatan dan Bahan}

Bahan utama yang digunakan pada penelitian ini yaitu buah tomat (Solanum lycopersicum) yang diperoleh dari pasar tradisional dan VCO. Bahan lainnya yaitu campuran larutan kloroform-metanol (p.a) dengan perbandingan 70:30 (v/v), $\mathrm{NH}_{4} \mathrm{SCN}$ (Merck), $\mathrm{FeCl}_{2}$ (Merck), hidrogen peroksida $\left(\mathrm{H}_{2} \mathrm{O}_{2}\right)$ (Merck), $\mathrm{HCl} 10 \mathrm{M}$, serbuk besi dan aquades.

Alat yang digunakan pada penelitian ini yaitu spektrofotometri UV-Vis Perkinelmer L850, neraca analitik Ohaus Corp. Pine Brook, 
kain saring, termometer, panci, kompor, baskom, blender, talang aluminium, dan pisau.

\section{Prosedur Penelitian}

\section{Produksi ekstrak likopen (Daniel et al., 2017)}

Likopen kasar dari buah tomat dapat diproduksi dengan cara yaitu tomat yang sudah bersih ditimbang, kemudian ditambahkan dengan air dengan rasio air terhadap buah tomat (rasio air/buah tomat) 1:1 atas dasar volume per berat $(\mathrm{v} / \mathrm{b})$. Buah tomat dihancurkan menggunakan blender, lalu pasta tomat yang diperoleh dipanaskan pada suhu $70^{\circ} \mathrm{C}$ selama 30 menit, selanjutnya pasta tomat yang dihasilkan disaring lalu ampas atau residu yang dihasilkan dikeringkan dibawah sinar matahari. Residu yang sudah kering yang merupakan likopen kasar buah tomat lalu dihancurkan menggunakan blender lalu diayak menggunakan ayakan 60 mesh. Likopen kasar selanjutnya digunakan sebagai bahan campuran VCO.

\section{Pencampuran Likopen dan VCO (Indriani et al., 2018)}

Likopen kasar yang telah dihaluskan dimasukkan ke dalam botol vial dan dicampurkan dengan VCO dengan perbandingan 40:1, 40:2 dan 40:3 (v/b). Selanjutnya campuran dikocok dan didiamkan selama 5 minggu dengan taraf masing-masing pengamatan yaitu 0 minggu, minggu ke-1, minggu ke-2, minggu ke-3, minggu ke-4 dan minggu ke-5. Parameter yang diukur sebagai variabel terikat adalah bilangan peroksida.

\section{Pembuatan Larutan Stok Fe (IDF, 1991)}

Larutan stok $\mathrm{Fe}$ dibuat dengan cara melarutkan 0,05 gram serbuk besi ke dalam 5 $\mathrm{mL} \mathrm{HCl} 10 \mathrm{M}$, kemudian ditambahkan $0,5 \mathrm{~mL}$ larutan hidrogen peroksida 30\%. Larutan tersebut dipanaskan selama 5 menit lalu didinginkan hingga mencapai suhu kamar, kemudian ditepatkan dengan aquades dalam labu ukur $50 \mathrm{~mL}$. konsentrasi larutan ini sebesar $1 \mathrm{mg} / \mathrm{mL}$ atau $1000 \mathrm{~g} / \mathrm{L}$. larutan stok $\mathrm{Fe}$ dengan konsentrasi $10 \mathrm{mg} / \mathrm{L}$ didapat dengan cara mengencerkan $0,5 \mathrm{~mL}$ larutan yang telah dibuat sebelumnya (konsentrasi $1000 \mathrm{~g} / \mathrm{L}$ ) dengan larutan campuran kloroform dan metanol ke dalam labu ukur $50 \mathrm{~mL}$. Pembuatan serial larutan standar dilakukan dengan cara ke dalam 5 labu ukur $10 \mathrm{~mL}$ masing-masing dipipet $0 \mathrm{~mL}, 2 \mathrm{~mL}, 4 \mathrm{~mL}, 6$ $\mathrm{mL}$ dan $8 \mathrm{~mL}$ larutan stok $\mathrm{Fe} 10 \mathrm{mg} / \mathrm{L}$ kemudian ditambahkan $0,05 \mathrm{~mL}$ larutan $\mathrm{NH}_{4} \mathrm{SCN}$ dan $0,05 \mathrm{~mL}$ larutan $\mathrm{FeCl}_{2}$, kemudian diencerkan dan ditepatkan dengan larutan campuran kloroform dan metanol. Setelah 5 menit, mengukur absorbansi masing-masing larutan menggunakan spektrofotometri pada panjang gelombang $500 \mathrm{~nm}$. Nilai korelasi yang diperoleh sebesar 0,996 .

\section{Analisis bilangan peroksida (IDF, 1991)}

Sebanyak 0,3 gram sampel dimasukkan ke dalam erlenmeyer, lalu ditambahkan dengan $10 \mathrm{~mL}$ campuran kloroform dan metanol dan 0,05 $\mathrm{mL} \mathrm{NH}_{4} \mathrm{SCN}$ kemudian absorbansinya diukur pada panjang gelombang $500 \mathrm{~nm}\left(\mathrm{E}_{0}\right)$. Sebanyak $0,05 \mathrm{~mL}$ larutan $\mathrm{FeCl}_{2}$ ditambahkan, kemudian larutan dikocok dan didiamkan selama 5 menit lalu mengukur absorbansinya pada panjang gelombang $500 \mathrm{~nm}\left(\mathrm{E}_{2}\right)$. Campuran kloroformmetanol digunakan sebagai blanko.

Sebanyak 0,05 $\mathrm{mL} \mathrm{NH}_{4} \mathrm{SCN}$ dan $0,05 \mathrm{~mL}$ $\mathrm{FeCl}_{2}$ ditambahkan $10 \mathrm{~mL}$ campuran kloroform dan metanol, didiamkan selama 5 menit kemudian mengukur absorbansinya pada panjang gelombang $500 \mathrm{~nm}\left(\mathrm{E}_{1}\right)$. Perbedaan absorbansi (y) ditentukan dengan menggunakan rumus: 


$$
y=E_{2}-\left(E_{1}+E_{0}\right)
$$

Perbedaan absorbansi sampel digunakan untuk menentukan konsentrasi $\mathrm{Fe}$ pada sampel berdasarkan kurva standar. Nilai perbedaan absorbansi kemudian dimasukkan ke dalam persamaan kurva standar $(y=a+b x)$ dari serial larutan standar yang telah didapatkan sebelumnya untuk mengetahui konsentrasi Fe yang terbaca pada sampel. Konsentrasi sampel dari kurva standar ( $\mathrm{x}$ ) disebut juga $\mathrm{m}$. Bilangan peroksida sampel (milligramekuivalen oksigen per kilogram) dapat ditentukan dengan rumus menggunakan rumus :

Bilangan Peroksida $=\frac{m \times 1000}{55,84 \times m o} \times 0,0101$

Keterangan :

$\mathrm{m}=$ konsentrasi Fe pada sampel (mg/L)

mo = massa sampel $(\mathrm{g})$

$55,84=$ massa relatif $\mathrm{Fe}(\mathrm{g} / \mathrm{mol})$

1000 = faktor konversi $(1000 \mathrm{~g} / \mathrm{kg})$

$0,0101=$ volume akhir larutan dalam kuvet $(\mathrm{L})$

\section{HASIL DAN PEMBAHASAN}

Hasil penelitian diperoleh likopen kasar buah tomat dengan berat 75 gram dalam bentuk serbuk. Pengukuran absorbansi untuk menentukan bilangan peroksida pada blending VCO-likopen kasar buah tomat dilakukan dengan menggunakan spektrofotometri pada panjang gelombang $500 \mathrm{~nm}$.

Pada minggu 0 untuk rasio 40:1 dengan tiga kali pengulangan diperoleh bilangan peroksida dengan nilai rata-rata 4,40 meq $\mathrm{O}_{2} / \mathrm{kg}, 1,62$ meq $\mathrm{O}_{2} / \mathrm{kg}$ untuk rasio 40:2 dan rasio 40:3 bernilai 0,08 meq $\mathrm{O}_{2} / \mathrm{kg}$ (Gambar 1 ). Perbedaan besarnya nilai peroksida yang diperoleh disebabkan karena adanya perbedaan jumlah kadar likopen yang terdapat dalam minyak VCO.

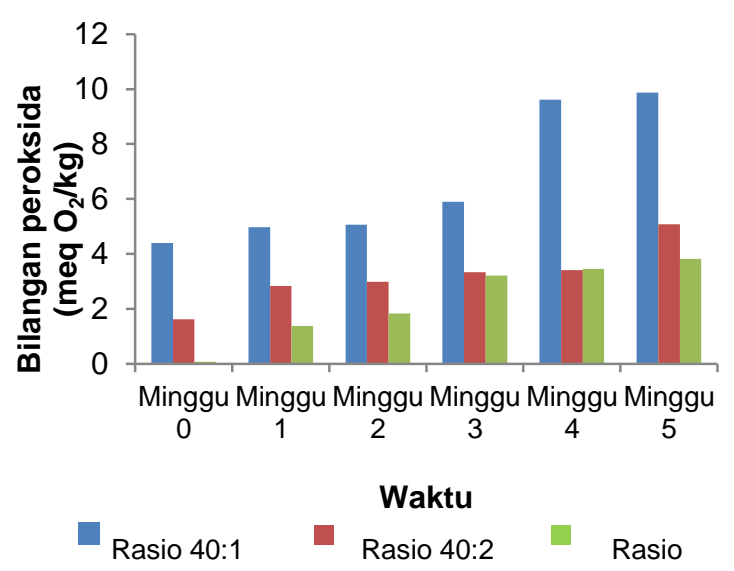

Gambar 1. Bilangan peroksida VCO pada rasio 40:1, 40:2, dan 40:3 selama penyimpanan hingga 5 minggu

Semakin banyak penambahan likopen maka bilangan peroksida pada minyak VCO akan semakin kecil. Hal tersebut terjadi karena likopen dengan jumlah yang lebih banyak akan lebih efektif menghambat oksidasi VCO. Hasil yang diperoleh pada rasio VCO:likopen 40:3 pada nol minggu lebih baik dibandingkan penelitian Momuat et al. (2009) yang menambahkan $10 \%$ ekstrak tomat dalam VCO dengan bilangan peroskida $0,145 \mathrm{meq} \mathrm{O}_{2} / \mathrm{kg}$. Penggunaan rasio VCO:likopen 40:3 hingga minggu ke-5 mampu menekan fluktuasi bilangan peroksida pada angka 3,83 meq $\mathrm{O}_{2} / \mathrm{kg}$.

Selain, pengaruh rasio, nilai bilangan peroksida VCO juga dipengaruhi oleh lama penyimpanan. Semua bahan pangan apabila disimpan pada waktu tertentu akan mengalami kerusakan tidak terkecuali pada VCO. Semakin lama penyimpanan kualitas VCO akan berkurang, salah satu faktor penentu kualitas suatu minyak yaitu bilangan peroksida (Ketaren, 1986). Bilngan peroksida VCOlikopen meningkat seiring dengan bertambahnya lama penyimpanan VCO (Gambar 1). Hal yang sama juga terjadi pada VCO tanpa penambahan ekstrak likopen. 
Bilangan peroksidannya meningkat seiring bertambahnya waktu penyimpanan (Gambar 2).

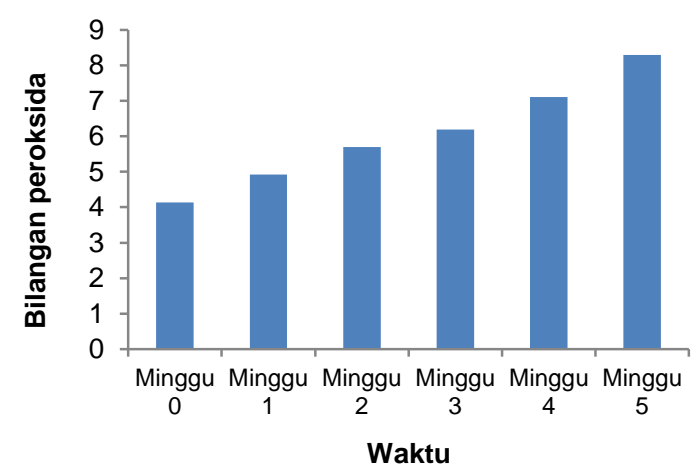

Gambar 2. Bilangan peroksida VCO tanpa ekstrak likopen selama penyimpanan hingga 5 minggu

Pada minggu ke-1, dari ketiga sampel dengan konsentrasi 40:1, 40:2 dan 40:3 diperoleh nilai bilangan peroksida dengan ratarata masing-masing secara berurutan yaitu 4,97 meq $\mathrm{O}_{2} / \mathrm{kg}, 2,84$ meq $\mathrm{O}_{2} / \mathrm{kg}$, dan 1,38 meq $\mathrm{O}_{2} / \mathrm{kg}$ (Gambar 1). Peningkatan nilai bilangan peroksida yang signifikan terjadi di minggu ke-3 pada sampel dengan konsentrasi $40: 1$, rata-rata nilai bilangan peroksida dengan konsentrasi $40: 1$ yaitu 5,90 meq $\mathrm{O}_{2} / \mathrm{kg}$ sedangkan di minggu ke-4 rata-rata nilai bilangan peroksida yang diperoleh dengan konsentrasi yang sama yaitu sebesar 9,62 meq $\mathrm{O}_{2} / \mathrm{kg}$. Selain itu pada konsentrasi sampel 40:3, kenaikan bilangan peroksida juga nampak signifikan dari minggu ke 2 ke minggu ke 3. Bilangan peroksida di minggu ke 2 yaitu sebesar 1,84 meq $\mathrm{O}_{2} / \mathrm{kg}$ sedangkan pada minggu ke 3 bilangan peroksida sampel sebesar 3,21 meq $\mathrm{O}_{2} / \mathrm{kg}$.

Bilangan peroksida pada VCO tanpa ekstrak likopen lebih besar dibandingkan dengan minyak VCO yang ditambahkan ekstrak likopen, akan tetapi pada minggu ke 4 dan minggu ke 5 pada sampel dengan rasio 40:1 bilangan peroksidanya lebih besar dibandingkan yang tanpa penambahan ekstrak likopen, hal ini mungkin dikarenakan likopen yang terdapat pada VCO telah mengalami degradasi. Degradasi likopen terjadi karena terjadi oksidasi oleh oksigen diudara (Febriansyah et al., 2008).

\section{KESIMPULAN}

Perbandingan rasio VCO:likopen dan waktu peyimpanan berpengaruh terhadap bilangan peroksida VCO. Nilai bilangan peroksida terendah pada penyimpanan $0,1,2$, 3 , 4, dan 5 minggu diperoleh pada rasio 40:3 $(\mathrm{v} / \mathrm{b})$ dengan nilai berturut-turut $0,08 \mathrm{meq}$ $\mathrm{O}_{2} / \mathrm{kg}, 1,38$ meq $\mathrm{O}_{2} / \mathrm{kg}, 1,84$ meq $\mathrm{O}_{2} / \mathrm{kg}, 3,21$ meq $\mathrm{O}_{2} / \mathrm{kg}, 3,46$ meq $\mathrm{O}_{2} / \mathrm{kg}$ dan 3,83 meq $\mathrm{O}_{2} / \mathrm{kg}$. Hingga minggu ke-5 penggunaan rasio 40:3 mampu menekan proses oksidasi VCO dengan nilai bilangan peroksida 3,83 meq $\mathrm{O}_{2} / \mathrm{kg}$, dibandingkan VCO tanpa penambahan likopen dapat mencapai bilangan peroksida $8,29 \mathrm{meq}_{2} / \mathrm{kg}$.

\section{DAFTAR PUSTAKA}

Cikita, I., Hasibuan, I., \& Hasibuan, R. (2016). Pemanfaatan Flavonoid Ekstrak Daun Katuk (Sauropus androgynus (L) Merr) Sebagai Antioksidan Pada Minyak Kelapa. Jurnal Teknik Kimia USU, 5(1): 45-51.

Daniel, K., Mappiratu, M., \& Sumarni, N. K. (2017). Penentuan Masa Kadaluarsa Likopen dari Buah Tomat (Lycopersicum pyriforme) Tercampur Maltodekstrin Dalam Kemasan Kapsul. KOVALEN, 3(3): https://doi.org/10.22487/j24775398.2017 .v3.i3.9331

Febriansyah, R., Indryani, L., Palupi, K., \& Ikawati, M. (2008). Tomat (Solanum Lycopersium L.) Sebagai Agen Kemopreventif Potensial. (diunduh di http://ccrc.farmasi.ugm.ac.id/wpcontent/uploads/rifki_tomat-paper.pdf, pada tanggal 19 Desember 2019) 
IDF. (1991). International Standard 74A, Method Determination of Peroxide Value in Anhydrous Milk Fat. International Dairy Federation, Brussels.

Indriani, E., Ruslan, R., Prismawiryanti, P., \& Satrimafitrah, P. (2018). Kadar Likopen Ekstrak Kasar Buah Tomat dalam Vco (Virgin Coconut Oil) pada Perendaman Suhu Ruang. KOVALEN: Jurnal Riset Kimia, 4(2): 174-179. https://doi.org/10.22487/kovalen.2018.v 4.i2.10226

Ketaren, S. (1986). Pengantar Teknologi Minyak dan Lemak Pangan. Ul-Press, Jakarta.

Koski, A., Psomiadou, E., Tsimidou, M., Hopia, A., Kefalas, P., Wähälä, K., \& Heinonen, M. (2002). Oxidative Stability and Minor Constituents of Virgin Olive Oil and Cold-Pressed Rapeseed Oil. European Food Research and Technology, 214(4): 294-298.

https://doi.org/10.1007/s00217-001-

0479-5

Mappiratu, Nurhaeni, \& Israwaty, I. (2010). Pemanfaatan Tomat Afkiran Untuk Produksi Likopen. Media Litbang Sulawesi Tengah, 3(1): 64-69.

Momuat, L. I., Wuntu, A., Hatidja, D., Runtu, M., \& Lengkong, V. (2009). Kualitas Minyak Kelapa dengan Penambahan Ekstrak Tomat pada Beberapa Waktu Penyimpanan dan Suhu Pemanasan. Jurnal Ilmiah Sains, 9(1): 149-156. https://doi.org/10.35799/jis.9.1.2009.299 10

Nodjeng, M., Fatimah, F., \& Rorong, J. A. (2013). Kualitas Virgin Coconut Oil (VCO) yang Dibuat pada Metode Pemanasan Bertahap sebagai Minyak Goreng dengan Penambahan Wortel (Daucus carrota L.). Jurnal IImiah Sains, 13(2): 102-109. https://doi.org/10.35799/jis.13.2.2013.305 3

Wenli, Y., Yaping, Z., Zhen, X., Hui, J., \& Dapu, W. (2001). The Antioxidant Properties of Lycopene Concentrate Extracted from Tomato Paste. Journal of the American Oil Chemists' Society, 78(7): 697-701. 